\title{
Socio-Economic Development Approach for Implementation of Cloud Computing in E-Governance
}

\author{
Mrs. Vaishali Kadu ${ }^{1}$, Mr. C. P. Kadu ${ }^{2}$ \\ Assistant Professor, Sinhgad Institute of Management, Vadgaon BK, Pune, Maharashtra, India ${ }^{1}$ \\ Assistant Professor, Sau. Venutai Chavan Polytechnique, Vadgaon BK, Pune, Maharashtra, India ${ }^{2}$
}

\begin{abstract}
The Government is committed towards overall development of all sections of society. The Ministry of Social Justice and Empowerment works towards educational development, economic and social empowerment of needy people. India is a country of villages and to improve and sustain the overall prosperity, growth and development in the global competitive regime, National E-governance plan (NEGP) seeks to lay the foundation with various projects, starting from the grass-root levels, and provide impetus for long-term e-governance within the country. In this direction rural e-Governance applications implemented in the recent few years have been demonstrating the importance of Information and Communication Technologies (ICT) in the concerned areas of rural development. Indeed, some of the schemes introduced in rural India have improved the government services immensely. This paper how implementation of cloud computing will increase social and economic development of India.
\end{abstract}

Keywords: Cloud Computing, e-Governance, Socio-Economic Development.

\section{INTRODUCTION}

E-Governance is the application of information \& political, technical and cultural reasons. E-governance communication technologies to transform the efficiency, requires applications to be secure and protect the privacy effectiveness, transparency and accountability of of end users

informational \& transactional exchanges with in government, between govt. \& govt. agencies of National, State, Municipal \&Local levels, citizen \& businesses, and to empower citizens through access \& use of information.

\section{TYPES OF E-GOVERNANCE APPLICATIONS}

Government to Government (G2G): Various functions of the government interact to fulfill the work. Majority of these applications are both vertical and horizontal. Vertical applications target a specific application of the government and horizontal make it. These applications have a high degree of message passing across departments.

Government to Enterprise (G2E): Enterprises like Water Board, Electricity are controlled by the governments and should react quickly to government policies. Policy enforcements, security and auditing (for accountability) are the biggest challenges.

Government to Business (G2B): Government interacts with various business in terms of policy enforcement, collection of taxes, contract management etc.

Government to consumer (G2C): Government provides numerous services to their citizens. Different departments offer various services that could scale from a simple request resolution to starting workflow related scenarios. E-governance requirements may be driven by economic,

\section{WHY CLOUD COMPUTING FOR E- GOVERNANCE}

The Cloud provides a solid foundation for the introduction of robust, scalable, and easily available e-Governance applications.

- The Cloud provides faster, cheaper and seamless eGovernance services, accelerating the adoption and use of IT for e-services.

- Applying Cloud architectures on current data centers would dramatically improve resource utilization and reduce total operational costs (OPEX).

- Monitoring data centers for traffic and resource utilization is crucial for adoption of Cloud Computing architectures for e-Governance.

- Service Level Agreements (SLA) to monitor e-service availability.

- E-governance application creators should consider people, process and technology and come up with comprehensive processes, and standards to be followed when managing the Cloud for e-Governance infrastructure.

- Properly applied Cloud architectures in e-Governance applications can transform the nation into an Information Society and smart cities. 


\section{WHAT IS CLOUD COMPUTING}

Cloud computing is a model for enabling ubiquitous, convenient, on-demand network access to a shared pool of configurable computing resources (e.g., networks, servers, storage, applications, and services) that can be rapidly provisioned and released with minimal management effort or service provider interaction.

\section{Cloud Computing Delivery Models}

i. Software as a Service (SaaS): The consumer uses an application, but does not control the operating system, hardware or network infrastructure on which it's running. Cloud offers applications as a service. For E-Governance solution for some application for their citizens. There is no need to purchase applications, hardware and software. They can make a request for a particular service from the cloud provider. Applications instances can then be created for their use. Numerous applications can be provided as standard services, where departments can request and manage. Some of the applications can be:

- Complaint Resolution System

- Employee Management Systems

- Attendance Resolutions Systems

- E-police, E-court

- Municipal Maintenance

- Water Boards, Billing, Payment Systems

- District Management Solutions

- Service Desk

Cloud fits in right into the requirements and can offer excellent service in this regard. Instead of each department hosting hardware, software and applications, they can get all the applications for a district instantly to be provisioned and operational. Hence cloud accelerates the implementation of e-Governance services. This one feature can reduce the cost of e-Governance

\section{ii. Platform as a Service (PaaS):}

The consumer uses a hosting environment for their applications. The consumer controls the applications that run in the environment (and possibly has some control over the hosting environment), but does not control the operating system, hardware or network infrastructure on which they are running. The platform is typically an application framework.

Cloud offers standard platforms in terms of providing different kinds of systems, middleware and integration systems. Some of the standard platforms they provide are:

- OS provisioning

- Queuing Service

- Database Services

- Middleware Services

- Workflow Services

Government departments requiring resources can request and get resources instantly as compared to traditional methods where they have to wait till they purchase, deploy etc.
Applications requiring middleware services can be provided instantly.

iii. Infrastructure as a Service (IaaS): The consumer uses "fundamental computing resources" such as processing power, storage, networking components or middleware. The consumer can control the operating system, storage, deployed applications and possibly networking components such as firewalls and load balancers, but not the cloud infrastructure beneath them. Infrastructure as a service virtualizes the hardware/ network and storage aspects of the datacenter.

A e-Governance requires a $24 \times 7$ infrastructure availability minimizing downtime. e-Governance applications can assume unlimited supply of CPU, storage and bandwidth when operating from cloud. Application designers can focus on features and usability instead of worrying about scalability etc. Still, applications perform better on cloud compared to traditional architecture.

Cloud architecture is build on SOA principles Cloud computing offers unlimited supply of CPU, storage and bandwidth Application designers are free to focus on features and usability

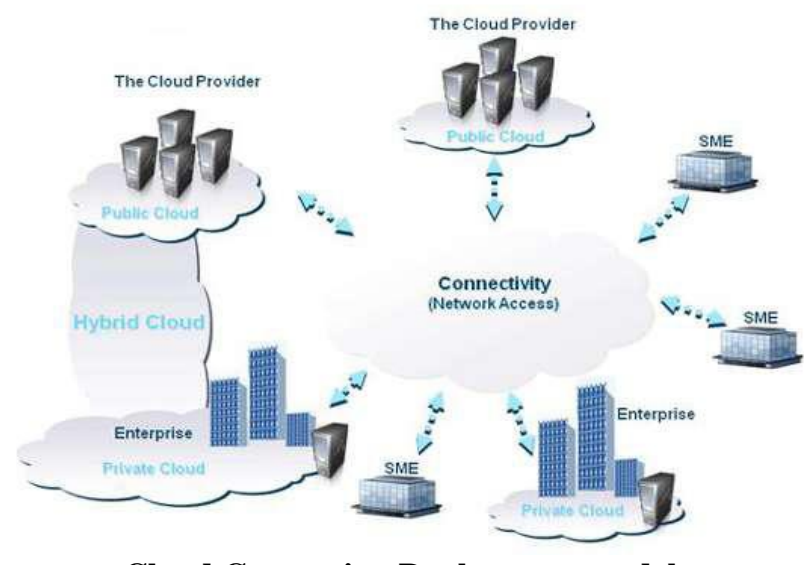

Cloud Computing Deployment models

\section{CLOUD COMPUTING \\ CHARACTERISTICS}

ESSENTIAL

i. Rapid Elasticity: Elasticity is defined as the ability to scale resources both up and down as needed. To the consumer, the cloud appears to be infinite, and the consumer can purchase as much or as little computing power as they need. This is one of the essential characteristics of cloud computing in the NIST definition. ii. Measured Service: In a measured service, aspects of the cloud service are controlled and monitored by the cloud provider. This is crucial for billing, access control, resource optimization, capacity planning and other tasks.

iii. On-Demand Self-Service: The on-demand and selfservice aspects of cloud computing mean that a consumer can use cloud services as needed without any human interaction with the cloud provider.

iv. Ubiquitous Network Access: Ubiquitous network access means that the cloud provider's capabilities are 
Vol. 6, Issue 1, January 2017

available over the network and can be accessed through standard mechanisms by both thick and thin clients. v. Resource Pooling: Resource pooling allows a cloud provider to serve its consumers via a multi-tenant model. Physical and virtual resources are assigned and reassigned according to consumer demand. There is a sense of location independence in that the customer generally has no control or knowledge over the exact location of the provided resources but may be able to specify location at a higher level of abstraction (e.g., country, state, or
datacenter).

e. For the government, two domains should also be considered

i. Enterprise (i.e. NGEN)

ii. Tactical (i.e. CANES)

\section{HOW E-GOVERNMENT CAN HELP IN SOCIAL DEVELOPMENT}

\section{Increasing Transparency}

1. Dissemination of Government rules and procedures, citizen's charter, government performance to a wider audience

2. Disclosure of public assets, government budget, and procurement information

3. Making decisions and actions of civil servants transparent

\section{Reducing Administrative Corruption}

1. Putting procedures online so that transactions can be easily monitored

2. Reduce the gatekeeper role of civil servants through automated procedures that reduce discretionary powers

3. Eliminate the need for intermediaries

Improving Service Delivery

1. Less time in completing transactions

2. Reduce costs associated with travel for citizens to interact with government

3. Improve government ability to deliver service to larger segment of population

\section{Empowerment}

1. Provide un served communities (limited access to government) with a new channel to receive government services and information

2. Reduce the brokerage power of intermediaries

\section{How E-Government Can Help in Economic} Development

Streamlining administrative process

1. Increase ability of managers to monitor task completion rates of civil servants

2. Improve efficiency of civil servants by automating tedious work

3. Integration of databases, reducing inaccuracies caused by the presence of redundant, duplicate databases

4. Increase speed and efficiency of inter-and intra-agency workflow and data exchange Reducing Administrative

\section{Burdens for businesses}

1. Faster access to government and less time needed to interact with government.

2. Reduction of interlocutors between government and individual.

Increasing Revenue

1. Make it convenient to pay taxes

2. Improved audit to identify defaulters

3. Plug leakage by reducing corruption

Cost Reduction and Budget Savings

1. Reduce Cost of transactions for government processes

2. Provide Better Control of Expenditure

\section{MAJOR SOCIAL DEVELOPMENT USING E- GOVERNMENT}

1) Increased Transparency and Reduced Corruption

The Central Vigilance Commission in India, a government agency designed to monitor corruption, created a website that publishes the names of officers from the elite administration and revenue services against whom investigation have been ordered. The website received a lot of attention because the press used the information to highlight corruption cases to a national audience. While there are concerns that public officials may be smeared wrongly through the website, the tool has had a big impact in highlighting corruption.

\section{Reduction of Bribes}

Anticorruption Project

Ability to track the processing of an application for service (those that are not delivered across the counter) by citizens has increased transparency. Supervisors can also track unusual behavior.

Collect citizen feedback on corruption. Taking away discretion to delay or deny by automating the process.

Keeping a traceable electronic record of transaction reduces the opportunity for corrupt practices and increases accountability of public officials in Karanataka .

Reduction of Powerful Brokers CARD in AP, Department of Transport in India Make procedures simple and transparent Reduce processing time Remove gate keeping role. Raising Public Awareness Central Vigilance Commission Website in India Publishing names of corrupt Publishing performance of prosecuting agencies Teacher's Transfer in Karnataka

\section{MAJOR ECONOMIC DEVELOPMENT USING E-GOVERNMENT}

Cost Reduction in Service Delivery

Without a critical mass using the application, particularly for revenue generating applications such as taxes, or feebased services, cost recovery does not seem promising. However, experience has shown that even rural poor citizens are willing to pay a reasonable fee for a useful service. There are a few examples such as Bhoomi project 
Vol. 6, Issue 1, January 2017

in Karnataka where farmers pay a transaction fee of 30 cents for receiving a signed copy of land title from an online kiosk. In the first year 5.5 million farmers have collected the tile, forking out nearly 2 million dollars, which is half the cost of the entire project.

\section{Control of Government Expenditure}

Many countries have implemented integrated financial management systems to track and control payments made out of Government treasuries. For example the state of Karnataka has connected all its 215 treasuries through a satellite based network. Every payment is now centrally authenticated to ensure that a budget provision exists for the payment and that it is not exceeded. Such systems focus on expenditure control, not exploiting the full potential of the system to combat corruption and improve service delivery.

Experience suggests that it is difficult to implement IFIMIS as they are complex and need to be comprehensive in their scope to deliver concrete benefits through online tax filing and processing system, governments aim to reduce the corruption and enhance transparency to create more public trust.

\section{CONCLUSION}

Instances like Mahatma Gandhi National Rural Employment Guarantee Act (MGNREGA), Warana Project in Maharashtra, Online Income Tax, Online Central Excise, Unique ID and E-office has accelerated growth of respective areas and contributing to country's economic development. Similarly, at state level the various rural E-governance projects such as SETU Project in Maharashtra etc, projects that have been providing excellent services and saving time and money of people as well as of government and are contributing their might to the socio-economic development of rural India.

The vast majority, however, is yet to awaken to the potential of e-government for reform. A major task is to build institutional capacity for governance reform.

The overall social and economic impact of e-government in developing countries may at best be marginal (if measured through progress on human development and economic indicators) because the investments that have been made so far are small. Scholars have not attempted to measure this impact as perhaps it is too early to do so. It is therefore difficult to make a recommendation that investment in e-government should be stepped up to a certain level. E-Government can advance the agenda on governance and economic reform, transparency, anticorruption, empowerment and poverty reduction. EGovernment should not be seen as a panacea for the complex and well-entrenched problems of corruption and poverty. These problems require multi-pronged action. EGovernment is one of the many tools whose potential in tackling these problems needs to be recognized. EGovernment provides an entry point for reform minded politicians, as it is able to make a dent on some of these problems without a head on confrontation with the vested interests that would like to preserve the status quo. Several successful projects that were referred to in this report have shown that gains from E-Government can be real but implementation requires a lot of administrative effort. The challenge is to promote widespread use.

\section{REFERENCES}

[1] SpeG, A society for promotion of e-Governance

[2] [http://www.egovindia.org/egovernancepaper.doc]

[3] General Services Administration, Federal Cloud Computing Services, Cloud FAQ

[4] Technology in Government by Jaijit Bhattacharya

[5] Global Government Cloud Computing Roundtable," Cloud Computing and the Canadian Environment", http://www.scribd. com/doc/20818613/Cloud-Computing-and-the-CanadianEnvironment

[6] "Cloud Computing for E-Governance" A white paper, IIIT Hyderabad, India

[7] Government of India, „Information Technology Action Plan: IT for All Indians by $2008^{\text {ee }}$,http://it-taskforce.nic.in.

[8] CLOUD COMPUTING STRATEGIC DIRECTION PAPER Opportunities and applicability

[9] The Economic and Social Impact of E-government

[10] Subhash Bhatnagar Professor Indian Institute of Management, Ahmedabad (June 2003 A background technical paper for the proposed UNDESA publication )

[11] Senthilkumaran, S. and Arunachalam, Subbiah, Expanding the Village Knowledge Centres in Pondicherry, Regional Development Dialog, Autumn 2002 and Etta, Florence, Thioune, Ramata Aw., with Adera, Edith, Case Study of Acacia Telecentres: Senegal and Uganda, regional Development Dialog, Autumn 2002.

[12] The center is a non-partisan, non-p rofit research group based in Washingt on, D.C. conducts computer-based research on campaign finance issues for the news media, academics, activists, and the public at large. The Center's work is aimed at creating a more educated voter, an involved citizenry, and a more responsive government.

[13] http://www1.worldbank.org/publicsector/egov/cvc_cs.htm

[14] Khajane in Egovernance: South Gets Serious http://www. expresscomputeronline.com/20021028/bangalore3.shtml

[15] Bill Dorotinsky, Integrated Financial Management System: An Important But Limited Anti-Corruption Tool http://www1.worldbank.org/publicsector/egov/anticoregovseminar/ bill\%20transprency $\% 20$ and $\% 20$ ifms.doc

[16] M. Shell. (2002) IEEEtran homepage on CTAN. [Online]. Available: http://www.ctan.org/tex-archive/macros/latex/ contrib. /supported/ IEEEtran/

[17] FLEXChip Signal Processor (MC68175/D), Motorola, 1996.

[18] "PDCA12-70 data sheet," Opto Speed SA, Mezzovico, Switzerland.

[19] Karnik, "Performance of TCP congestion control with rate feedback: TCP/ABR and rate adaptive TCP/IP," M. Eng. thesis, Indian Institute of Science, Bangalore, India, Jan. 1999.

[20] J. Padhye, V. Firoiu, and D. Towsley, "A stochastic model of TCP Reno congestion avoidance and control," Univ. of Massachusetts, Amherst, MA, CMPSCI Tech. Rep. 99-02, 1999.

[21] Wireless LAN Medium Access Control (MAC) and Physical Layer (PHY) Specification, IEEE Std. 802.11, 1997. 